\title{
Functional magnetic resonance imaging and diffusion tensor imaging findings in a patient with ROBO3-related horizontal gaze palsy with progressive scoliosis
}

Achados de functional magnetic resonance imaging e diffusion tensor imaging em um paciente com paralisia da mirada horizontal com progressiva escoliose, relacionado ao gene ROBO3

Fabricio Castro de BORBA1', Brunno Machado de CAMPOS², João Pedro Nunes GONÇALVES ${ }^{3}$,

Carlos Roberto MARTINS JUNIOR, Marcondes Cavalcante FRANCA JUNIOR ${ }^{1}$

A 24-year-old-woman woman presented with birth-onset horizontal gaze ophthalmoplegia. Past medical history was unremarkable. Her brother had similar findings with severe progressive scoliosis, requiring surgery. After 12 years of follow-up, the patient developed mild head tremor which did not bother her and nightmare disorders that was successfully treated with nortriptyline. Spine X-rays revealed mild scoliosis. Whole exome analysis revealed c.906-17G >A mutation in $R O B O 3$ splicing site,
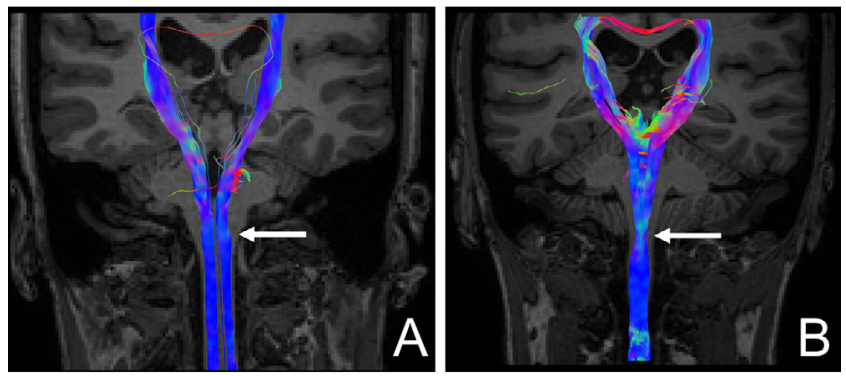

Figure 1. Diffusion tensor imaging tractography with adjusted parameters to evaluate the brainstem and the upper portion of the spinal cord. (A) Arrow indicates the absence of corticospinal tracts decussation in a patient with ROBO3related horizontal gaze palsy with progressive scoliosis. (B) Diffusion tensor imaging tractography obtained from a healthy subject at Universidade Estadual de Campinas (Neuroimaging Laboratory database). Arrow highlights normal appearance of pyramidal decussation. confirming horizontal gaze palsy with progressive scoliosis (HGPPS). Diffusion tensor imaging (DTI) tractography revealed parallel non-decussating corticospinal tracts (Figure 1A), which markedly diverges from healthy controls (Figure 1B). Motor task functional magnetic resonance imaging ( fMRI) revealed ipsilateral activation of the primary motor cortex (Figure 2).
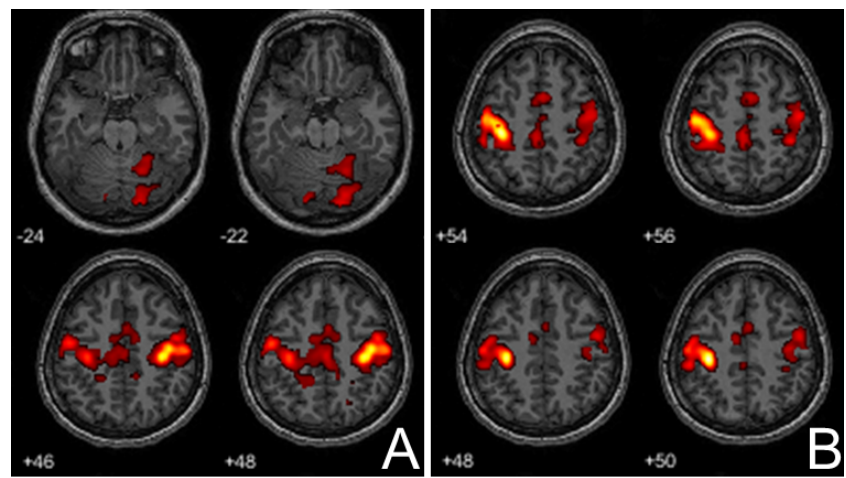

Figure 2. Functional magnetic resonance imaging images obtained from a patient with ROBO3-related horizontal gaze palsy with progressive scoliosis (images printed in neurological convention). (A) Predominant right primary motor cortex activation (yellow) while performing right-hand motor task. It is also noticeable that cerebellar activation (red) is also ipsilateral, confirming it was not due to technical error. (B) Predominant left primary motor cortex activation (yellow) while performing left-hand motor task.

\footnotetext{
${ }^{1}$ Universidade Estadual de Campinas, Faculdade de Ciências Médicas, Departamento de Neurologia, Campinas SP, Brazil. ${ }^{2}$ Universidade Estadual de Campinas, Faculdade de Ciências Médicas, Laboratório de Neuroimagem, Campinas SP, Brazil. 3Universidade Estadual de Campinas, Faculdade de Ciências Médicas, Departamento de Genética Médica, Campinas SP, Brazil. FCB (iD) https://orcid.org/0000-0001-6846-4037; BMC (iD) https://orcid.org/0000-0003-1261-8257; JPNG (iD https://orcid.org/0000-0002-1806-0525; CRMJ (iD https://orcid.org/0000-0002-5097-8504; MCFJ (iD https://orcid.org/0000-0003-0898-2419

Correspondence: Marcondes Cavalcante França Junior; Email: mcfrancajr@uol.com.br.

Conflict of interest: There is no conflict of interest to declare.

Authors' contributions: FCB: contributed with conceptualization, data analysis, formal analysis, funding acquisition, investigation, methodology, project administration, validation and manuscript writing and reviewing; BMC: contributed with neuroimaging acquisition and analysis, managing software and advised on manuscript; JPNG: contributed with genetics investigation, methodology and validation, also helped with writing the mutation description for the manuscript; CRMJ: contributed with conceptualization of the project, review and writing of the manuscript; MCFJ: contributed with conceptualization of the project, review and supervision of all processes involved in development of the case report and the manuscript.

Received on June 04, 2021; Received in its final form on June 23, 2021; Accepted on July 18, 2021.
} 


\section{References}

1. Pinero-Pinto E, Pérez-Cabezas V, Tous-Rivera C, Sánchez-González $\mathrm{J}$-M, Ruiz-Molinero C, Jiménez-Rejano J-J, et al. Mutation in robo3 gene in patients with horizontal gaze palsy with progressive scoliosis syndrome: a systematic review. Int J Environ Res Public Health. 2020 Jun;17(12):4467. https://doi.org/10.3390/ijerph17124467
2. Scortegagna FA, Pacheco FT, Hoffmann Nunes R, Serpa A, Migliavacca MP, Rocha AJ. Case 278: Mutation in ROBO3 Gene Horizontal gaze palsy and progressive scoliosis. Radiology. 2020 Jun;295(3):736-40. 